\title{
Reflexiones sobre la Costa Caribe nicaragüense desde un enfoque histórico- regional
}

Dimas Antonio Delgado Alemán

Recepción: 05-06-2016 / Aceptación: 08-10-2016

Dimasantoniod04@gmail.com

\section{Resumen}

El objeto del presente artículo es reflexionar desde un enfoque histórico regional sobre las regiones autónomas del caribe nicaragüense, teniendo en cuenta su diversidad cultural, étnica, lingüística, y geográfica. Se toma como referencia teórica la perspectiva histórica-regional propuesta por Vizcaíno González, quien contempla la cohesión de todos los factores, internos y externos, que confluyen en la evolución histórica de una región, los cuales se combinan armónicamente y la integran como una totalidad. Desde esta perspectiva el estudio interpreta que la Costa Caribe nicaragüense con su diversidad cultural, étnica, lingüística, y geográfica, reúne las condiciones para ser abordada desde la perspectiva del enfoque histórico regional.

Para este estudio se tendrá en cuenta la especificidad de la evolución histórica de esta región en relación al resto de regiones del país. Una zona protagonista de muchos eventos que la han conformado como una entidad única, sin posibilidad de confundirse con otras localidades, de manera que su existencia no depende de otras regiones. Desde sus orígenes, hace más de cinco mil años, en esta región se asentaron pueblos provenientes del sur como los chibchas, y macrochibcha, culturalmente diferentes a los del pacífico de Nicaragua que provenían del norte. La presencia inglesa datada de 1616 es otro elemento distinto al resto del país. La poca incidencia de los españoles y la resistencia de los pueblos originarios a cualquier dominación también inciden en esta particularidad que se pretende estudiar de manera suscita.

Palabras claves: Región histórica, espacio geográfico, diversidad, interdisciplinariedad.

\begin{abstract}
The purpose of this article is to reflect from a regional historical focus on the autonomous regions of Nicaragua's Caribbean coast, taking into account their cultural, ethnic, linguistic, and geographic diversity. It was taken as reference the theoretical historical-regional perspective proposed by Vizcaino, who contemplates the cohesion of all factors, internal and external, that comes together in the historical evolution of a region, which combine harmoniously and they integrate as a whole. From this perspective, the study interprets that the Caribbean Coast of Nicaragua with its cultural, ethnic, linguistic, and geographic diversity, can be addressed from a regional historical approach. This study will take into account the specificity of the historical evolution of this region compared to other regions of the country. A protagonist area of many events that have shaped it as a single entity, without possibility of being confused with other localities. Since its beginnings, more than five thousand years ago, in this region settled towns from the south as the chibchas and Macrochibchas, culturally different from those of the Pacific of Nicaragua that came from the north. The English presence dating from 1616 is another element different from the rest of the country. The low incidence of the Spanish and the resistance of the native peoples to any domination, are also issues that are addressed in research
\end{abstract}

Keywords: Regional history, geographical space, diversity, interdisciplinary, Caribbean coast. 


\section{Introducción}

El presente artículo es una reflexión acerca de las posibilidades de realizar estudios con enfoque histórico regional sobre la costa caribe de Nicaragua, de manera particular en lo que se conoce en la actualidad como Región Autónoma de la Costa Caribe Norte (RACN) y Región Autónoma de la Costa Caribe Sur (RACS), teniendo en cuenta su diversidad cultural, étnica, lingüística, y geográfica. Para ello se analizan algunos aspectos de la evolución histórica de las regiones Autónomas de la Costa Caribe de Nicaragua: sus orígenes, pueblos chibchas, y macrochibchas, asentados en la zona, desde hace más de cinco mil años; la presencia inglesa datada desde 1616 hasta 1894; la resistencia de los pueblos Miskitos, Sumus, Ramas, Creoles, Garífonas que impidieron la presencia de los españoles en la región.

De igual manera se reflexiona sobre la histórica reincorporación de la Mosquitia realizado por la fuerza en 1894 por el gobierno del General José Santos Zelaya. Otro aspecto abordado tiene que ver con la característica geográfica constituida por un territorio de aproximadamente la mitad de la superficie del país, aunque poblacionalmente representa el 14\%; la generación de una conciencia identitaria como producto de esta evolución histórica-social construida a partir de sus luchas por sus reivindicaciones, hasta llegar al momento revolucionario (19791990) que le reconoce a la región caribe su autonomía en el año de 1987.

\section{Generalidades sobre historia regional}

En los estudios sobre historia regional suele haber cierta duda acerca de la interpretación del término región en sentido temporal. Pero también en cuanto al aspecto espacial al que hace referencia para su aplicación o explicación. Así por ejemplo, se habla de regiones las cuales difieren en cuanto a la dimensión territorial y donde criterios históricos culturales se mezclan con otros de tipo geopolíticos. De esta manera se habla de regiones continentales (Latinoamérica), regiones o (sub-regiones) que abarcan varios países (Centroamérica), el Caribe. De igual manera a lo interno de cada país se establecen criterios de regionalización obedeciendo a necesidades político-administrativo o militares, por ejemplo en la Nicaragua de los años 80 del siglo pasado, donde se establecieron nueve regiones.

La autora Lilian Vizcaíno González (s.f) señala que la historia regional:

(...) no corresponde siempre a un espacio menor al de un país, en tanto es un fenómeno observable a diferentes escalas. De modo que en ocasiones la región contempla un área mayor que puede abarcar incluso a un subcontinente $o$ conjunto de países como Latinoamérica, o una subregión como el Caribe; en fin depende de la existencia real de la región como producto histórico social y de los propósitos que persiga el investigador. (p. 121)

Igualmente, esta autora apunta que la región es para el historiador una realidad total, y que esta existe más allá de los postulados que al respecto se elaboren. Estima que es un producto social y no una invención del intelecto. (p.124)

Asimismo, los estudios regionales pueden verse desde una perspectiva inter /trans disciplinaria, que va desde enfoques sociológicos, espaciales, históricos, culturales, económicos, antropológicos, lingüísticos, políticos, entre otros, haciendo de esta una fuente inagotable de temáticas y anclajes disciplinar a tratar. Sin embargo, esta condición complejiza su abordaje. La flexibilidad o amplitud del término, hace que en los estudios histórico-regionales, las diferentes disciplinas se interrelacionen con mayor o menor profundidad cuando se analiza el fenómeno de forma integral. 
En relación a lo anterior, Morin (2001: 158) citado por De la Herrán (2011: 294-300) señala: "se trata a menudo de esquemas cognitivos que pueden atravesar las disciplinas, a veces con una virulencia tal que las pone en trance". Para De la Herrán, la complejidad de la interdisciplinariedad es inherente al proceso cognitivo porque "el enfoque congruente para su comprensión no es otro que transdisciplinar o incluso el superior (metadisciplinar)". (Pág.299)

Por su parte Vizcaíno González (s/f) concibe los estudios regionales desde la perspectiva de la integración de factores internos y externos que lo cohesionan como un todo:

(...) este producto social, es el resultado de un proceso histórico de conformación y delimitación, al que también se denomina regionalización y que comprende dos vertientes fundamentales: una de integración y otra de diferenciación. El integrador contempla la cohesión de todos los factores, internos y externos, que confluyen en la evolución histórica de la región, los cuales se combinan armónicamente y la integran como una totalidad. Mientras que el proceso diferenciador o individualizador es aquel durante el cual se definen los rasgos que distinguen a la región y que permiten apreciar su singularidad, lo que se constata únicamente en la comparación con otras regiones. (pág. 124)

A partir de estas reflexiones, el trabajo toma como referencia la perspectiva teórica sobre estudios histórico-regional propuesto por Vizcaíno. Su eje de estudio se aplica al análisis de la costa caribe nicaragüense dada su condición de región en cuyo espacio geográfico se identifica una evolución histórica propia de gran riqueza cultural.

\section{Evolución histórico-cultural de la región}

Los orígenes de los primeros habitantes de la costa caribe se extiende por lo menos desde 5600 años a. de C., hasta aproximadamente 1633 d. de C., fecha del contacto con los europeos (ingleses) en dicho territorio. $\mathrm{Su}$ origen está vinculado a grupos chibchas y macrochibchas provenientes del sur del continente. Abarca aproximadamente la mitad de la superficie del país, aunque en términos poblacionales tiene una de las densidades más bajas del país (Chow; 2007:53)

Romero (1995) en su obra Las sociedades del Atlántico de Nicaragua en los siglos XVII y XVIII expresa que:

A la llegada y establecimiento de los europeos, entre los siglos XVII y XVIII, el territorio se encontraba habitado por poblaciones de cazadores, pescadores y recolectores, ubicados de forma dispersa en pequeñas villas, a la orilla de los ríos y en las áreas costeras. Algunos estudios calculan que se encontraban distribuidos unos 10.000 individuos en una superficie de 60.000 Km. (pág. XXIV)

Estos datos nos proporcionan una perspectiva, bastante clara, sobre las formas de vida de estas poblaciones asentadas en este territorio y de sus creencias y hábitos tribales. Sin duda, la irrupción de los pueblos europeos (españoles e ingleses) y sus estilos de vida (desconcertantes, debido a sus intenciones expansionistas y esclavistas) significó para los originarios una ruptura de la cosmovisión de las cosas. Del mismo modo, que aconteció para los pueblos del Pacífico y Centro del país.

Cabe destacar que para el 2005, según el InstitutoNacionaldeInformacióny Desarrollo de Nicaragua INIDE, en el VIII censo de población y IV de vivienda, la población 
del Caribe nicaragüense representaba el $14 \%$. En este informe se estimó también la superficie de las dos regiones en $60,366 \mathrm{~km}^{2} \mathrm{y}$ una población de 620,680 habitantes. Para la Región Autónoma del Caribe Norte (RACN) $33,105.98 \mathrm{~km}^{2}$ y 314,130 habitantes, con una densidad poblacional de $9.5 \mathrm{hab} . / \mathrm{km}^{2}$. Para la Región Autónoma del Caribe Sur, 27,260.02 $\mathrm{km}^{2}$ de extensión y 306,550 habitantes, para una densidad poblacional de $11.2 \mathrm{hab} . / \mathrm{km}^{2}$. (p.29. Ver mapas de las regiones en anexos). La región del caribe nicaragüense posee una diversidad cultural, étnica y lingüística, siendo uno de los sitios de mayor diversidad étnica de todo el país. Cuenta con seis grupos étnicos al interior de su territorio a saber: Miskitos, Sumus, Ramas, Creoles, Garífonas y Mestizos (Historia de Nicaragua; 2007: 0153)

Hay que mencionar que durante la época colonial, los pueblos miskitos lucharon contra la corona española, y esto fue aprovechado por los ingleses para ejercer su presencia en la costa del caribe nicaragüense. Hubo una injerencia en la zona que determinó en gran medida ciertos procesos contradictorios y enfrentamientos que contribuyeron a forjar la identidad de estos pueblos originarios.

El contacto inglés con estos antiguos habitantes del caribe nicaragüense tiene un gran peso en la construcción de las identidades de estos pueblos, aunque nada fue color de rosa para llegar este estadio. Ghotme (2012, 50-51), refiere que:

En las primeras décadas del siglo XIX, los indios mosquitos mantenían aún su vieja hostilidad contra los hispanos y al mismo tiempo su vieja conexión amistosa con los ingleses de Jamaica y Belice (...). De hecho, hasta bien entrada la primera mitad del siglo XIX los indios [refiriéndose al pueblo miskito] se consideraban simbólicamente sujetos al Superintendente de Belice y este, a su vez, al gobernador de la colonia británica de Jamaica, a quienes los mosquitos definían como el "príncipe más grande del mundo". En realidad, los ingleses alentaron en la mosquitia una especie de reino amerindio soportado en las viejas estructuras sociopolíticas tribales de los pueblos nativos, la mayoría de ellos hostiles a la corona española (...). (pág. 50-51)

Esta relación estrecha entre el pueblo Miskito y la colonia británica también la recoge Izard Martínez (2014:140) quien comenta:

Las relaciones con los ingleses convirtieron a los Miskito en el grupo hegemónico de la zona, hasta el punto de constituir una atípica monarquía indígena, el Reino Miskito, sustentado por el poder colonial británico con el objetivo geoestratégico de disponer de una frontera militar con la enemiga potencia española. El reino indígena dominó la región hasta finales del siglo xviii, cuando Inglaterra se retiró de la misma como resultado de los acuerdos de paz con España. (pag.140)

Otro de los momentos de la evolución histórica de la costa Caribe en el siglo XIX tiene que ver con los conflictos de interés que confrontaron a las grandes potencias militares y económicas de ese entonces, como los Estados Unidos de Norte América y Gran Bretaña. Durante la primera mitad del siglo XIX, Inglaterra mantuvo su presencia en la Costa de la Mosquitia de Nicaragua con el fin de preservar sus intereses sobre el territorio que pensaban sería la ruta canalera. Para ello declararon un protectorado apoyando al Rey Mosco, bajo el pretexto de resguardar los intereses de dicha región. Posteriormente, con la firma del tratado Clayton-Bulwer, Estados Unidos e Inglaterra en 1850 ninguno de estos países podían hacer el canal interoceánico de forma unilateral.

Todos los hechos anteriores se daban sin tomar en cuenta la posición de los pueblos originarios de la Costa Caribe nicaragüense, 
ni al gobierno central. Estas situaciones contribuyeron a la conformación de una identidad regional y una conciencia identitaria, dentro de un proceso histórico de luchas por sus reivindicaciones frente a las injerencias externas.

En el año 2016 se cumple el 122 aniversario de la reincorporación de la Mosquitia (1894), al territorio nicaragüense ocupado por los ingleses, en ese entonces, bajo la figura del protectorado. Esta acción tiene como propósito la deposición del Rey Mosco y la aprobación del convenio de abolición de la Reserva.

A propósito de la "Reincorporación de la Mosquitia", por el presidente Zelaya, el autor Palazio (1999:91), citado por Pérez, Reyes et. Al (2007:371) afirma que:

En 1894 cuando el Gobierno del general José Santos Zelaya "incorporó" la Mosquitia, se inició una nueva relación entre la Costa Atlántica y el Estado nicaragüense. Con ese proceso de "incorporación", el Estado Nacional, impuso la pertenencia nacional que debían asumir los pueblos de la Costa Atlántica de conformidad con las regulaciones y leyes de Nicaragua. El Estado afirmó la identidad nacional que las formaciones socioculturales allí asentadas debían aceptar para entrar a la plena y efectiva afirmación de "nacionalidad" nicaragüense, trastocando con ello, la raíz misma de toda una evolución ancestral diferenciada (Pág.371).

Los acontecimientos de la "Reincorporación" de 1894 y el desmantelamiento de la figura de la "Reserva", determinaron los procesos históricos en la región caribeña del país. De igual manera, ha modelado formas de organización social, expresiones religiosas, políticas, lingüísticas, configurando una idiosincrasia que identifica a los miembros de esta comunidad de manera singular, capaz de ser reconocidos entre el resto de regiones del país.

Aunque esta "Reincorporación" debe de estudiarse contrastando las narrativas y argumentaciones que los intelectuales del Caribe nicaragüense han construido acerca de la relación "conflictiva", desde el punto de vista histórico con el estado central. De manera particular, la forma traumática y aún inconclusa, pese a los pasos positivos de la autonomía, que ha conllevado la integración al conjunto nacional (Frühling et. al. 2007).

\section{Regiones de la costa caribe de Nicaragua y su autonomía}

En el proceso de conformación histórica de esta región, cabe mencionar uno de los momentos más importantes, realizado por el estado, como una forma de reconocimiento y reivindicación de los derechos de las comunidades originarias de esta zona: la aprobación del Estatuto de Autonomía de las Regiones de la Costa Atlántica de Nicaragua, Ley No. 28 del 7 de septiembre de 1987 (Gaceta Diario Oficial, No. 238). Esta ley reconoce la multiculturalidad de la región, partiendo de los derechos a usar de manera libre y en términos de igualdad, sus lenguas originarias, derechos políticos, jurídico legales, y de participación ciudadana, preservando sus formas de organización y prácticas religiosas ancestrales.

La Ley 28 en los Considerando II, III, y V establece:

II-Que la Región Atlántica nicaragüense constituye aproximadamente el 50\% del territorio patrio $\mathrm{y}$, con cerca de trescientos mil habitantes representa el $9.5 \%$ de la población nacional, distribuida en: ciento ochenta y dos mil Mestizos de habla hispana; setenta $\mathrm{y}$ cinco mil Misquitos con su propia lengua; veintiséis mil Creoles de habla inglesa; nueve mil Sumos con su propia lengua; 
mil setecientos cincuenta Garifunas, la mayoría de los cuales han perdido su lengua, y ochocientos cincuenta Ramas de los cuales sólo treinta y cinco conservan su lengua.

III-Que la identidad multiétnica del pueblo nicaragüense está firmemente inspirada en las hazañas de héroes Indo-americanos como Diriangén, Cuauhtemoc, Caupolicán y Tupac Amaru que nunca claudicaron y en la gesta de Augusto C. Sandino quien sembró de esperanzas y determinación a los indígenas del Río Coco sus cooperativas agrícolas y mineras y quien orgullosamente al mundo proclamó: "Soy nicaragüense y me siento orgulloso porque en mis venas circula, más que todo, la sangre india que por atavismo encierra el misterio de ser patriota, leal y sincero".

V-Que el proceso de Autonomía enriquece la cultura nacional, reconoce y fortalece la identidad étnica; respeta las especificidades de las culturas de las Comunidades de la Costa Atlántica; rescata la historia de las mismas; reconoce el derecho de propiedad sobre las tierras comunales, repudia cualquier tipo de discriminación; reconoce la libertad religiosa $\mathrm{y}$, sin profundizar diferencias reconoce identidades diferenciadas para construir desde ellas la unidad nacional.

El autor Llanes (1995:74) citado por Pérez, Reyes y Palazio (2007:374-375), expresa que:

El punto de partida del proceso de discusión sobre la autonomía de la Costa Atlántica, fue el documento "principios y políticas para el ejercicio de los derechos de Autonomía de los pueblos y comunidades de la Costa Atlántica nicaragüense", cuyo borrador sirvió de texto básico para la consulta a los pobladores del atlántico. Este documento contenía ideas centrales sobre la forma en que se establecería una nueva relación política administrativa, entre el Estado nacional y las regiones autónomas y a su vez, enfocaba posibles marcos jurídico-legales de participación de las expresiones socioculturales de las comunidades étnicas y pueblos del Atlántico.

Este texto fue traducido e impreso en los idiomas más importantes de la región: español, inglés criollo, Sumo-mayagna y miskito, y se hizo llegar a todas las comunidades de la Costa Atlántica con el propósito de someterlo a la mayor divulgación posible. Se debe señalar también que para hacer el documento accesible a la población, fue adaptado para presentar sus ideas en un formato menos técnico, más popular, y fácil de leer y entender.

Para promover y garantizar la participación de todos los sectores de la Costa Atlántica en el proceso de consulta, la comisión de autonomía implementó básicamentecuatro formas participativas: visitas casa por casa; asamblea con sectores políticos económicos y sociales, asambleas comunales y asambleas regionales de representantes de las comunidades (pág.374-375).

En la actualidad este proceso socio-cultural continúa desarrollándose dentro de una concepción regional. La reglamentación de la ley en octubre de 2003 (La Gaceta, Diario Oficial No. 186) luego de grandes luchas de las comunidades, representa una forma de defensa de las formas de vida y cultura de estas comunidades dentro de un contexto nacional cada vez en constantes cambios debido, entre otras razones a los procesos de globalización a que están sometidas nuestras instituciones y sociedades. 


\section{Conclusiones}

La región Caribe de Nicaragua reúne las características para ser estudiada desde un enfoque histórico regional, pues posee un espacio geográfico que representa casi la mitad del territorio nacional, $60366 \mathrm{~km}^{2}$ y una población aproximada de 620,680 habitantes que representan del $14 \%$ de la población total del país.

Ha tenido una evolución histórica propia, diferente a la de otras regiones del país, pues su sus comunidades estuvieron al margen de la colonización española en el siglo XVI. La relación con sociedades europeas fue con los ingleses a principios del siglo XVII y de una manera particular. Eso dio lugar a la conservación de las sociedades y culturas de esta zona, contándose en la actualidad con una riqueza étnica y lingüística y cultural, representada en los pueblos Miskitos, Sumus, Ramas, Creoles, Garífonas y Mestizos.

Una zona donde se han protagonizado eventos de gran importancia para Nicaragua, y que tiene como sujetos a los miembros de las comunidades, entre ellas deben de recordarse, expresión organizativa como la del Reino Miskito, el sistema de Reserva bajo la tutela inglesa, la llegada de los moravos. Todo esto ha modelado, entre otras expresiones una entidad única y diversa

El régimen de autonomía (Ley 28) es uno de los hechos más importantes ocurrido en los últimos 30 años, vista como región, observándose avances en los procesos de integración real al proyecto de nación, fundamentalmente en los últimos años. No obstante, como se vislumbra en estudios recientes, los procesos de empoderamiento requieren de un mayor fortalecimiento institucional y de participación ciudadana, reconociendo sus particularidades de vida.

\section{Referencias bibliográficas}

Chow, A. (2007) Los grupos aborígenes de la Costa Caribe de Nicaragua. Historia de Nicaragua. Texto básico. Editorial Ciencias Sociales, UNAN. Grupo editorial Acento.

De La Herrán, A. (2011). Complejidad y Transdisciplinariedad. Revista Educação Skepsis, Formação Profissional. (Contextos de la formación profesional). 2 (1). 294-320 São Paulo: skepsis.org. Recuperado julio, 202016. De https://www.uam.es/personal_ pdi/fprofesorado/agustind/textos/ completrans.pdf

Dembicz, A. (s.f) Espacio, estudios regionales. Historia Regional. Textos compilados para el curso Epistemología y metodología para estudios regionales y locales. Programa de Doctorado en Historia con Mención en Estudios Regionales y Locales Transdisciplinarios. (2015). Universidad Nacional Autónoma de Nicaragua, UNAN, Managua Facultad de Humanidades y Ciencias Jurídicas.

Estatuto de Autonomía de las Regiones de la Costa Atlántica de Nicaragua, Ley No. 28 del 7 de septiembre de 1987. Publicado en La Gaceta Diario Oficial, No. 238. Recuperado septiembre, 15, 2016. De http://legislacion. asamblea.gob.ni/normaweb.nsf / (\$All)/9F88A9114C4CA12F062570A10 0578099?OpenDocument.

Frühling, P., González, M., Buvollen, H.P. (2007). Etnicidad y nación. El desarrollo de la autonomía de la Costa Atlántica de Nicaragua (1987-2007). Guatemala: F \& G Editores.

Ghotme, Rafat. (2012). El Protectorado británico en la Costa Mosquitia, 18371849. RevistadeRelaciones Internacionales, Estrategia y Seguridad, 7(1), 45-74. Recuperado agosto 16, 2016, de: http:/ / www.scielo.org.co/scielo. php?script $=$ sci_arttext\&pid $=$ S190930632012000100003\&lng=en\&tlng=es

Izard Martínez G. (2014) Autonomía, ciudadanía multicultural y derechos 
colectivos en la Costa Atlántica de Nicaragua. Boletín Americanista, año lxiv. 2 (69), Barcelona. págs. 135-155, ISSN: 0520-4100

Instituto Nacional de Información y Desarrollo de Nicaragua INIDE, en el VIII censo de población y IV de vivienda 2005. Recuperado mayo, 18, 2015. De www.inide.gob.ni/censos 2005/ resumencensal/resumen2.pdf.

López, H. A. (2009) El caso de Mosquitia: Del Protectorado al intento de secesión. Secesionismos. Blosgpot Los nuestramericanos, su historia. Recuperadooctubre,05,2016.Dehttp:/ / www.centrocultural.coop/blogs / nuestramericanos/2009/08/20/elcaso-de-mosquitia-del-protectoradoal-intento-de-secesion/

Pérez, R., Reyes, J., y Palazio, E. (2007) La Nicaragua Reciente. El marco jurídico de la Revolución Popular Sandinista. Historia de Nicaragua Texto básico. Editorial Ciencias Sociales, UNAN. Grupo editorial Acento.

Romero Arrechavala, J. [et al.] (2007) Historia de Nicaragua. Texto básico. Editorial Ciencias Sociales, UNAN. Grupo editorial Acento.

Romero Vargas, G. (1995) Las Sociedades del Atlántico de Nicaragua en los siglos XVII y XVIII. Colección Cultural Banco Nicaragüense. Managua.

Vizcaíno González, L. (sf) La historia regional. Mitos y realidades. Revista Tzintzun, $N^{\circ}$. 27. Revista de Estudios Históricos, ISSN: 1870-719X. Universidad Michoacana de San Nicolás de Hidalgo México. Recuperado agosto 30, 2016. De http://tzintzun.iih.umich.mx/ num_anteriores/pdfs/tzn27/historia_ regional_annales.pdf.

www.ineter.gob.ni . Instituto Nicaragüense de Estudios Territoriales, INETER. (2003) Mapa político de Nicaragua. Recuperado agosto, 20 2016. De http:// www.ineter.gob.ni/Geodecia/mapas_de_ los_departamentos_listas.html

Instituto Nicaragüense de Estudios Territoriales, INETER. (2003) Mapa de la región Atlántico Norte. Recuperado agosto, 20 2016. De http://www. ineter.gob.ni/Geodecia/files/raan.jpg

Instituto Nicaragüense de Estudios Territoriales, INETER. (2003) Mapa de la región Atlántico Sur. Recuperado agosto, 20 2016. De http://www. ineter.gob.ni/Geodecia/files/raas.jpg

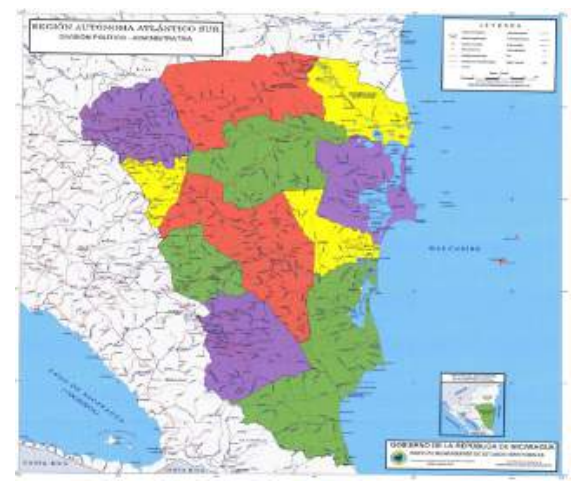

Fuente: Instituto Nicaragüense de Estudios Territoriles INETER. Mapa de la Región Autónoma Atlántico Sur http://www.ineter.gob.ni/Geodecia/files/raas.jpg

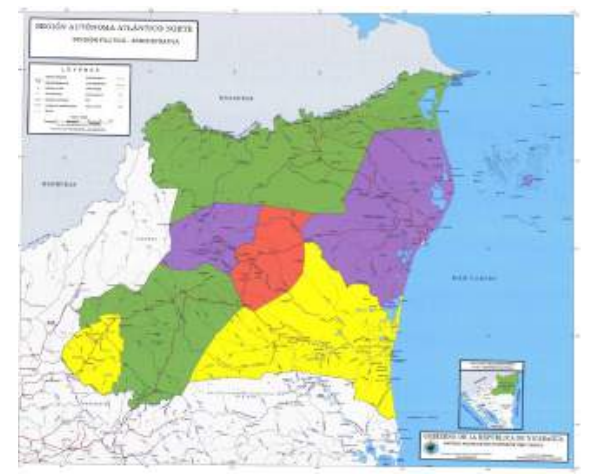

Fuente:Instituto Nicaraguense de Estudios Territoriles. INETER. (2003) Mapa de la región Atlántico Norter. Tomado de http://www.ineter.gob.ni/Geodecia/files/raan.jpg

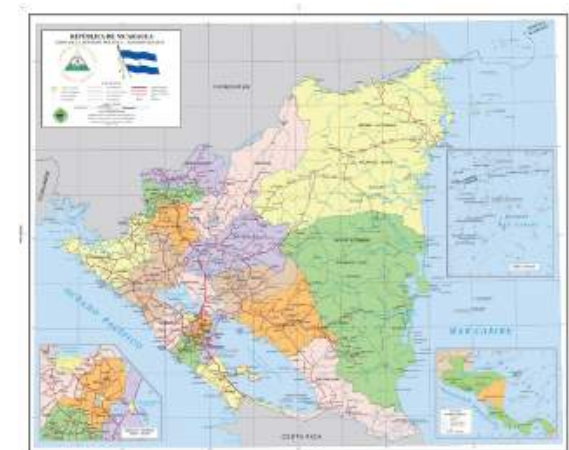

Fuente: Instituto Nicaragüense de Estudios Territoriles, INETER. (2003) Mapa político de Nicaragua. Tomado de http://www.ineter.gob.ni/Geodecia/mapas de los departamentos_listas.html 